\title{
Effect of prophylactic timolol $0.1 \%$ gel on intraocular pressure after an intravitreal injection of ranibizumab: a randomized study
}

This article was published in the following Dove Press journal:

Clinical Ophthalmology

17 June 2016

Number of times this article has been viewed

\section{Alfredo Pece' \\ Davide Allegrini' \\ Giovanni Montesano² \\ Andrea Fabio \\ Dimastrogiovanni'}

'Eye Clinic, Melegnano Hospital, Vizzolo Predabissi, ${ }^{2}$ Eye Clinic, San Paolo Hospital, Università di Milano, Milano, Italy
Correspondence: Davide Allegrini Eye Clinic, Melegnano Hospital, Via Pandina I, 20070 Vizzolo Predabissi, Milano, Italy

Tel $+39028|84430|$

$\mathrm{Fax}+390250323150$

Email davideallegrini@yahoo.it
Purpose: The purpose of this study is to make a prospective evaluation of the effect of timolol $0.1 \%$ eye gel on short-term intraocular pressure (IOP) after an intravitreal injection (IVI) of ranibizumab.

Participants and methods: One hundred and fifty eyes of 150 IVI-naïve patients with macular edema caused by various pathological conditions (age-related macular degeneration, central or branch retinal vein occlusion, and diabetic retinopathy) were scheduled to undergo an IVI of ranibizumab $(0.5 \mathrm{mg} / 0.05 \mathrm{cc})$. The patients were randomly divided into three groups: 50 were not treated with timolol before the IVI (group 1); 50 received an instillation of timolol $0.1 \%$ eye gel the evening before the IVI (group 2); and 50 received an instillation of timolol $0.1 \%$ eye gel 2 hours before the IVI (group 3). The incidence of clinically significant intraocular hypertensive spikes ( $>25 \mathrm{mmHg}$ and $>40 \mathrm{mmHg}$ ) was then assessed.

Results: Our findings showed that mean IOP at baseline was significantly higher than at both 5 and 60 minutes after IVI $(P<0.01)$. Spikes of $>25 \mathrm{mmHg}$ were recorded at either time in 27 patients (54\%) in group 1, 23 patients (44\%) in group 2, and 24 patients (48\%) in group 3. None of the between-group differences were significant. Spikes of $>40 \mathrm{mmHg}$ (which were only detected 5 minutes after IVI) were recorded in nine (18\%), eight (16\%), and one patient $(2 \%)$ in groups 1,2 , and 3 , respectively. The only significant difference was between the control and group $3(P=0.012)$.

Conclusion: An increase in IOP after antivascular endothelial growth factor IVI is a frequent complication. The prophylactic use of timolol $0.1 \%$ gel effectively reduced the mean IOP when administered 2 hours before IVI and was also effective in preventing dangerous IOP spikes of $>40 \mathrm{mmHg}$. It is therefore recommended before IVIs as a means of preventing emergency procedures and preserving the health of the optic nerve.

Keywords: macular edema, pressure spikes, anti-VEGF therapy, pressure-lowering medication

\section{Introduction}

Intravitreal antivascular endothelial growth factor (VEGF) injections are currently used to treat macular edema and suppress neovascularization in the case of many eye diseases. ${ }^{1-3}$ Given the increase in the indications for anti-VEGF agents and the fact that a larger number of patients being treated usually require repeated intravitreal injections (IVIs), it is important to identify any adverse effects.

The most frequent complications of IVIs are subconjunctival and vitreal hemorrhages, corneal edema, conjunctival scars, retinal tears and detachment, lens damage, development of cataracts, choroidal rupture, ocular hypertension, and endophthalmitis. ${ }^{4,5}$ The injection of anti-VEGF fluid into the vitreous cavity is expected to increase the intraocular 
pressure (IOP), ${ }^{6-10}$ and although this is usually transient, it occasionally persists. ${ }^{7,9-14}$ Both MARINA and ANCHOR trials found transient post-IVI increases in IOP in the treatment groups, although very few patients experienced an increase of $\geq 40 \mathrm{mmHg}$; however, the injection protocols did not require IOP measurements within 1 hour of the injections, and so the increase in IOP during this time was not reported. ${ }^{15,16}$

We evaluated the short-term effect of topical prophylaxis with timolol $0.1 \%$ (Timoge ${ }^{\circledR}$ preservative-free eye gel, THEA, Clermont-Ferrand, France) on short-term IOP changes in patients receiving IVIs of ranibizumab (Lucentis ${ }^{\circledR}$; Novartis International AG, Basel, Switzerland).

\section{Participants and methods}

This prospective study included all the patients who were referred to the Eye Unit of Melegnano Hospital (Milan, Italy) between September 2013 and September 2014. All the procedures performed in this study involving human participants were in accordance with the ethical standards of the institutional and/or national research committee and with the 1964 Declaration of Helsinki and its later amendments or comparable ethical standards. The ethics approval was deemed not necessary by the Ethics Committe of Melegnano Hospital, in accordance to Italian law as our work did not involve particular changes in existing procedures in our clinical practice, and as the drug used is not an experimental product, but widely used and already used at our hospital.

One hundred and fifty IVI-naïve patients were affected by macular edema caused by age-related macular degeneration, central or branch retinal vein occlusion, or diabetic retinopathy and were scheduled for treatment with ranibizumab (Lucentis $0.5 \mathrm{mg} / 0.05 \mathrm{cc}$ ).

The patients were randomly divided into three groups: 50 were not treated with timolol before the IVI (group 1); 50 received an instillation of timolol $0.1 \%$ eye gel the evening before the IVI (group 2); and 50 received an instillation of timolol $0.1 \%$ eye gel 2 hours before the IVI (group 3). The exclusion criteria were a history of glaucoma, ocular hypertension or treatment with an IOP-lowering medication, intraocular surgery in the previous 3 months, corneal diseases, or active intraocular inflammation.

All the patients underwent a complete ophthalmic examination including the measurement of best corrected visual acuity, a study of the oculi of the anterior segment and fundus, angiography with fluorescein (Heidelberg Retina Angiograph; Heidelberg Engineering, Heidelberg, Germany), and optical coherence tomography (Spectral optical coherence tomography/scanning laser ophthalmoscope; OPKO/OTI, Miami, FL, USA).
All the IVIs were performed under topical anesthesia in operating rooms by two surgeons who were familiar with the procedure; both the surgeons used the same technique and were blinded to the group assignments of the patients. Ranibizumab was administered using a 30-gauge needle following the international guidelines for IVIs. ${ }^{17}$ Prior to receiving the injection, the patients gave their written informed consent after being informed about its use, efficacy, and complications; none of them received steroid medications before or immediately after IVI, and none required paracentesis.

IOP was measured 15 days before, 5 minutes, and 1 hour after the IVI using Goldmann applanation tonometry (Model AT 900 C/M; Haag-Streit, Switzerland) with the patients in a sitting position, and spikes of $>25 \mathrm{mmHg}$ and $>40 \mathrm{mmHg}$ were recorded.

The between-group differences in mean IOP at the two post-IVI times were analyzed using analysis of variance for repeated measures (a multivariate mixed model including the treatment group and the time of measurement as fixed factors and the subject as the random grouping factor) in order to determine the correlations between the measurements made in the same subject. The mean IOP values in each group were compared at each time point, and the values at the two time points were compared within each group. The $P$-values were obtained by comparing the marginal mean values obtained from a single linear model (using the $\mathrm{R}$ package lsmeans).

Subsequently, logistic univariate or multivariate regression was used to analyze the incidence of hypertensive spikes. In this analysis, binary coding was used to identify all the subjects whose IOP was $>25$ or $>40 \mathrm{mmHg}$ at either time after the injection, and these binary variables were then modeled as a binomial response within the framework of a classical logistic regression from which the odds ratios were derived. This therefore, tested the probability of the subjects in each group having an IOP value that was higher than the specified threshold of $25 \mathrm{mmHg}$ (Table 1) or $40 \mathrm{mmHg}$ (Table 2) rather than the differences in frequencies. Spike frequencies are given in Table 1 in order to make it easier to interpret the results. Each treatment group were compared with the control group as the reference group.

\section{Results}

The mean age ( \pm standard deviation) of the patients in groups 1,2 , and 3 was $71.4( \pm 9.6), 71.6( \pm 9.5)$, and $70.3( \pm 9.2)$ years, respectively. The percentage of females $(60 \%, 54 \%$, and $52 \%$, respectively) and pseudophakic eyes $(60 \%, 64 \%$, and $60 \%$, respectively) was similar in the three groups (Table 3 ), as was the mean baseline IOP and the trends of IOP. 
Table I Spike occurrence

\begin{tabular}{|c|c|c|c|c|}
\hline Variable & Arm & After 5 minutes & After 60 minutes & At any time \\
\hline \multirow{3}{*}{ Patients with spike $>25 \mathrm{mmHg}$ (n [\%]) } & Untreated & $27(54.0)$ & $6(12.0)$ & $27(54.0)$ \\
\hline & Timogel given the evening before & $22(44.0)$ & $8(16.0)$ & $23(46.0)$ \\
\hline & Timogel given 2 hours before & $24(48.0)$ & I (2.0) & $24(48.0)$ \\
\hline \multirow[t]{3}{*}{ Patients with spike >40 mmHg (n [\%]) } & Untreated & $9(18.0)$ & - & $9(18.0)$ \\
\hline & Timogel given the evening before & $8(16.0)$ & - & $8(16.0)$ \\
\hline & Timogel given 2 hours before & I (2.0) & - & I (2.0) \\
\hline
\end{tabular}

Abbreviation: -, not included.

The highest mean IOP values in groups 1,2 , and 3 were recorded 5 minutes after IVI $(29.3 \pm 12,28.3 \pm 9.9$, and $25.5 \pm 6.4 \mathrm{mmHg}$, respectively), which were higher than at baseline $(15.1 \pm 1.6,15.3 \pm 1.6$, and $15.5 \pm 1.9 \mathrm{mmHg}$, respectively) and after 60 minutes $(18.7 \pm 5.4,18.8 \pm 5.9$, and $17.3 \pm 3.9 \mathrm{mmHg}$, respectively). At each time point, mean IOP was significantly higher than that at baseline $(P<0.01)$, except in group 3 $(P=0.23)$. None of the patients required paracentesis to control the hypertensive spikes. Mean IOP after 5 minutes was $13 \%$ lower in group 3 (which received timolol $0.1 \%$ gel 2 hours before the IVI) than in the control group $(P=0.008)$ (Table 4).

Table 3 shows the incidence of clinically significant intraocular hypertensive spikes $(>25$ or $>40 \mathrm{mmHg}$ ) in the three groups. The number of patients with spikes of $>25 \mathrm{mmHg}$ was similar in groups 1,2 , and $3(\mathrm{n}=27,54 \%$; $\mathrm{n}=23,44 \% ; \mathrm{n}=24,48 \%$, respectively), which was slightly higher in the control group. Spikes of $>40 \mathrm{mmHg}$ were only detected after 5 minutes, and their incidence was more heterogeneous ( $n=9,18 \% ; n=8,16 \% ; n=1,2 \%$, respectively), the lowest being found in group 3 . The significance of the difference in the number of hypertensive spikes was tested using univariate and multivariate logistic regression ("Materials and methods" section for details). A series of univariate analyses tested the possible associations between the control variables (age, sex, concomitant diseases, and pseudophakia) and the incidence of hypertensive spikes (Tables 2 and 5), and the control variables that proved to be significant at univariate analysis were included in the multivariate analysis (only sex was excluded). The multivariate logistic regression showed no significant difference between the two treated groups and the controls in terms of preventing IOP from increasing to $>25 \mathrm{mmHg}$ at any time. Only pseudophakia had a significant protective effect against spikes of $>25 \mathrm{mmHg}$ (hazard ratio $[\mathrm{HR}]=0.2, P<0.01$ ).

The same analysis was used to analyze the differences in the number of hypertensive spikes of $>40 \mathrm{mmHg}$ and showed that the administration of timolol $0.1 \% 2$ hours before the procedure significantly reduced them in comparison with the control group $(P=0.012)$. The administration of timolol $0.1 \%$ the evening before the procedure did not lead to any significant advantage $(P=0.73)$. Pseudophakia was significantly associated with the incidence of IOP spikes of $>40 \mathrm{mmHg}(P=0.0002)$, against which it was highly protective (HR $=0.01$, whereas age was a major risk factor $(\mathrm{HR}=4.74, P=0.047)$ (Tables 2 and 5).

\section{Discussion}

The MARINA and ANCHOR studies of the efficacy of antiVEGF IVIs initially found no sustained increase in IOP, ${ }^{15,16}$ but it is known that high IOP levels are a frequent complication

Table 2 Association with spike $>40 \mathrm{mmHg}$ occurrence after 5 minutes

\begin{tabular}{|c|c|c|c|c|}
\hline \multirow[t]{2}{*}{ Variable } & \multicolumn{2}{|l|}{ Univariate } & \multicolumn{2}{|l|}{ Multivariate } \\
\hline & HR (95\% Cl) & $P$-value & HR (95\% Cl) & $P$-value \\
\hline Age (for each 10-year increase) & $0.45(0.26-0.77)$ & 0.004 & $4.74(1.02-22.0)$ & 0.047 \\
\hline \multicolumn{5}{|l|}{ Sex } \\
\hline Female (reference) & I & & & \\
\hline Male & $0.43(0.15-1.29)$ & 0.132 & - & - \\
\hline \multicolumn{5}{|l|}{ Concomitant pathology } \\
\hline DM + other (reference) & I & & I & \\
\hline AMD & $4.14(1.46-11.8)$ & 0.008 & $10.3(1.09-98.2)$ & 0.042 \\
\hline Pseudophakia & $0.03(0-0.21)$ & 0.0005 & $0.01(0-0.009)$ & 0.0002 \\
\hline \multicolumn{5}{|l|}{ Arm } \\
\hline Untreated (reference) & I & & I & \\
\hline Timogel given the evening before & $0.87(0.30-2.47)$ & 0.790 & $0.79(0.20-3.06)$ & 0.735 \\
\hline Timogel given 2 hours before & $0.09(0.01-0.76)$ & 0.027 & $0.06(0.01-0.54)$ & 0.012 \\
\hline
\end{tabular}

Abbreviations: AMD, age-related macular degeneration; $\mathrm{Cl}$, confidence interval; DM, diabetes maculopathy; HR, hazard ratio; - , not included. 
Table 3 Patient characteristics

\begin{tabular}{|c|c|c|c|c|}
\hline Variable & Untreated & $\begin{array}{l}\text { Timogel given the } \\
\text { evening before }\end{array}$ & $\begin{array}{l}\text { Timogel given } \\
2 \text { hours before }\end{array}$ & $P$-value \\
\hline Number of patients ( $\mathrm{n}[\%]$ ) & $50(33.3)$ & $50(33.3)$ & $50(33.3)$ & - \\
\hline \multicolumn{5}{|l|}{ Age, years } \\
\hline Mean $( \pm S D)$ & $71.4( \pm 9.6)$ & $71.6( \pm 9.5)$ & $70.3( \pm 9.2)$ & 0.78 \\
\hline Min-max & $44-86$ & $49-88$ & $53-87$ & \\
\hline Female (n [\%]) & $30(60.0)$ & $27(54.0)$ & $26(52.0)$ & 0.70 \\
\hline Pathology (n [\%]) & & & & 0.94 \\
\hline AMD & $34(68.0)$ & $31(62.0)$ & $30(60.0)$ & 0.69 \\
\hline DM & I4 (28.0) & $17(34.0)$ & $18(36.0)$ & 0.67 \\
\hline Other* & $2(4.0)$ & $2(4.0)$ & $2(4.0)$ & - \\
\hline Pseudophakia (n [\%]) & $30(60.0)$ & $32(64.0)$ & $30(60.0)$ & 0.89 \\
\hline
\end{tabular}

Notes: *Other: four branch retinal vein occlusion (two control and two timolol $0.1 \%$ gel 2 hours before); two central retinal vein occlusion (two timolol $0.1 \%$ gel evening before).

Abbreviations: AMD, age-related macular degeneration; DM, diabetic maculopathy; min-max, minimum-maximum values; SD, standard deviation; - , not included.

of IVI treatment. Gismondi et a ${ }^{18}$ prospectively studied 54 eyes of 54 patients by measuring IOP immediately before and 5 seconds, 5, 10, 15, 30, and 60 minutes, and 1 day after receiving a ranibizumab IVI: at the seven post-IVI time points, IOP was > $21 \mathrm{mmHg}$ in $100 \%, 79.6 \%, 70.4 \%, 59.3 \%, 46.3 \%$, $20.4 \%$, and $0 \%$ of the eyes, respectively, and $>30 \mathrm{mmHg}$ in $88.9 \%, 29.6 \%, 16.7 \%, 7.4 \%$, and $0 \%$ of the eyes, respectively. Kim et al ${ }^{8}$ studied 120 eyes of 112 patients (including 20 glaucomatous patients) who received IVIs of ranibizumab, bevacizumab, pegaptanib, or triamcinolone acetonide: mean IOP was $44 \mathrm{mmHg}$ (range: 4 to $87 \mathrm{mmHg}$ ) immediately after the injection, but decreased to $<30 \mathrm{mmHg} 30$ minutes later. The changes in the mean IOP from baseline of all the three groups in our study were significant at 5 and 60 minutes after the injection, and other studies of short-term IOP changes have also found that it tends to return to a safe level in the majority of patients $10-30$ minutes postinjection. ${ }^{7,919}$

The pathogenesis of short-term increases in IOP after anti-VEGF IVIs are most directly related to the increase in intraocular fluid volume, ${ }^{20}$ but Gismondi et al also found a relationship with a shorter axial length and other potential variables influencing IOP which included scleral thickness, scleral rigidity, and ocular outflow capacity. ${ }^{21}$
It has been found that an acute increase in IOP proportionally decreases optic nerve head and juxtapapillary retinal blood flow ${ }^{22}$ and blocks axonal transport to the optic nerve head in animal models. ${ }^{23}$ The implications of these findings are not clear but include possible ganglion cell loss, especially in patients with glaucoma or other optic neuropathies. ${ }^{24}$ We believe that IOP spikes can affect the health of the optic nerve in subjects with advanced glaucomatous optic neuropathy as previous studies have found that clear visual field progression, ${ }^{25}$ and even the loss of fixation, are associated with short-term IOP spikes following cataract surgery. ${ }^{26}$

There is disagreement in the literature concerning the need for paracentesis to prevent IOP spikes ${ }^{1,6,7,9,27-29}$ because it is invasive, unclear whether it should be performed pre- or postinjection, and not devoid of risk of the patients (it takes longer than an IVI, and complications such as endophthalmitis, lens damage, and cataract are more frequent). Prophylactic antiglaucomatous medications may be safer and easier, but it is not clear which drug is the most effective, and there is no consensus about routine prophylaxis.

The aim of this study was to determine whether the prophylactic use of timolol $0.1 \%$ gel is effective in reducing the IOP spikes after a ranibizumab IVI because most of

Table 4 Intraocular pressure trend over time

\begin{tabular}{|c|c|c|c|c|c|}
\hline Variable & $\begin{array}{l}\text { Baseline } \\
\text { mean }( \pm S D) \\
\text { min-max }\end{array}$ & $\begin{array}{l}+5 \text { minutes } \\
\text { mean }( \pm S D) \\
\text { min-max }\end{array}$ & $\begin{array}{l}\text { P-value } \\
\text { (vs baseline) }\end{array}$ & $\begin{array}{l}+60 \text { minutes } \\
\text { mean }( \pm S D) \\
\text { min-max }\end{array}$ & $\begin{array}{l}\text { P-value } \\
\text { (vs baseline) }\end{array}$ \\
\hline Untreated & $15.1( \pm 1.6) 10-18$ & $29.3( \pm 12.0) 15-66$ & $<0.0001$ & $18.7( \pm 5.4) \mid 2-36$ & 0.0022 \\
\hline Timogel given the evening before & $15.3( \pm 1.6) 10-18$ & $28.3( \pm 9.9) \quad 16-52$ & & $18.8( \pm 5.1) \quad 10-32$ & \\
\hline$P$-value (vs control) & 0.99 & 0.69 & $<0.0001$ & 0.99 & 0.0031 \\
\hline Timogel given 2 hours before & $15.5( \pm 1.9) 8-19$ & $25.5( \pm 6.4) \quad 16-54$ & & $|7.3( \pm 3.9)| 0-3 \mid$ & \\
\hline$P$-value (vs control) & 0.94 & 0.0078 & 0.0031 & 0.49 & 0.23 \\
\hline
\end{tabular}

Abbreviations: min-max, minimum-maximum values; SD, standard deviation; vs, versus. 
Table 5 Association with spike $>25 \mathrm{mmHg}$ occurrence at any time

\begin{tabular}{|c|c|c|c|c|}
\hline \multirow[t]{2}{*}{ Variable } & \multicolumn{2}{|l|}{ Univariate } & \multicolumn{2}{|l|}{ Multivariate } \\
\hline & HR $(95 \% \mathrm{CI})$ & $P$-value & HR (95\% CI) & $P$-value \\
\hline Age (for each 10-year increase) & $0.56(0.39-0.82)$ & 0.002 & $1.03(0.52-2.03)$ & 0.927 \\
\hline \multicolumn{5}{|l|}{ Sex } \\
\hline Female (reference) & I & & & \\
\hline Male & $0.80(0.42-1.53)$ & 0.500 & - & - \\
\hline \multicolumn{5}{|l|}{ Concomitant pathology } \\
\hline DM + other (reference) & I & & I & \\
\hline AMD & $1.98(1.01-3.88)$ & 0.048 & I.II (0.39-3.18) & 0.838 \\
\hline Pseudophakia & $0.20(0.10-0.42)$ & $<0.0001$ & $0.20(0.07-.056)$ & 0.002 \\
\hline \multicolumn{5}{|l|}{ Arm } \\
\hline Untreated (reference) & I & & I & \\
\hline Timogel given the evening before & $0.73(0.33-1.59)$ & 0.424 & $0.74(0.32-1.72)$ & 0.478 \\
\hline Timogel given 2 hours before & $0.79(0.36-1.72)$ & 0.549 & $0.75(0.32-1.76)$ & 0.513 \\
\hline
\end{tabular}

Abbreviations: AMD, age-related macular degeneration; $\mathrm{Cl}$, confidence interval; DM, diabetes maculopathy; HR, hazard ratio; -, not included.

the studies investigating post-IVI IOP do not say whether IOP-lowering pretreatment was used or not. This is the first study that evaluates the efficacy of prophylactic pressurelowering treatment on post-IVI hypertensive spikes of $>25$ and $>40 \mathrm{mmHg}$, which are more indicative parameters for assessing the risk of post-IVI optic nerve damage than absolute variations in IOP. ${ }^{22-26}$ To the best of our knowledge, there are no previously published studies of the prophylactic use of timolol $0.1 \%$ gel for this purpose with which our findings could be compared.

Ozcaliskan et $\mathrm{al}^{30}$ studied 151 eyes of 151 patients to evaluate the effect of topical, fixed-combination of dorzolamide/timolol prophylaxis on short-term IOP changes in patients who had received a bevacizumab IVI. All the post-IVI IOP values were compared between the 75 eyes that received prophylaxis and the 76 eyes that were not pretreated: there was a significant between-group difference in IOP measured 1 minute after IVI $(P=0.04)$ and a statistically significant difference between the baseline and all the other recorded values, except those measured 60 minutes after IVI $(P<0.05) .^{30}$

Murray et a ${ }^{31}$ studied 24 patients with confirmed or suspected glaucoma who received oral acetazolamide $500 \mathrm{mg}$ or no treatment 60-90 minutes before a $0.5 \mathrm{mg}$ ranibizumab IVI for neovascular age-related macular degeneration, in order to determine whether the prophylaxis reduced the incidence and duration of post-IVI increases in IOP. The results showed a statistically significant reduction in IOP in the treated group, but only 30 minutes after the IVI. ${ }^{31}$

Kim et al ${ }^{32}$ studied 166 patients (175 eyes) scheduled for an anti-VEGF IVI, who were divided into three groups: group 1 (53 patients) received dorzolamide/timolol (Cosopt ${ }^{\mathbb{R}}$; Merck \& Co., Inc.; Kenilworth, NJ, USA) 1 hour before the procedure; group 2 (84 patients) received brinzolamide/ timolol (Elazop ${ }^{\circledR}$; Alcon Laboratories, Inc., Fort Worth, TX, USA); and group 3 (29 patients) received no prophylaxis. The IOP changes from baseline to 5 and 30 minutes after IVI were significant in all the three groups. The three groups were subdivided on the basis of whether they had received bevacizumab or ranibizumab, and all the six subgroups showed significant changes in IOP from baseline to 5 and 30 minutes after IVI. ${ }^{32}$ Unlike the aforementioned first two studies, this study did not compare the three groups with each other, but only the IOP changes over time in each group.

Frenkel et a ${ }^{33}$ studied 71 patients with exudative agerelated macular degeneration who received an anti-VEGF IVI of pegaptanib, ranibizumab, or bevacizumab. IOP-lowering medication was administered 1 hour before injection to $63 \%$, $74 \%$, and $66 \%$, respectively, of the patients in each IVI group; the remaining patients did not receive any prophylaxis. There were no statistically significant differences in IOP regardless of whether IOP-lowering premedication was used except for one interval (3-10 minutes, no medication versus two medications) in the pegaptanib group..$^{33}$ The type of prophylactic drug used for each patient was not specified, and, as in the other three studies, the effectiveness of prophylactic IOPlowering therapy on the post-IVI incidence of hypertensive spikes of $>25$ and $>40 \mathrm{mmHg}$ was not evaluated, but only the variations in IOP.

Timolol $0.1 \%$ is a beta-adrenergic antagonist that lowers IOP by decreasing the aqueous production of the ciliary body. ${ }^{34}$ It acts for 30-60 minutes after administration ${ }^{35}$ and, as it does not depend on the outflow capacity, it lowers IOP significantly even in the early postoperative period. Quaranta et $\mathrm{al}^{36}$ have found that both timolol maleate $0.5 \%$ solution administered twice daily and timolol $0.1 \%$ gel instilled once 
a day have similar and significant circadian efficacy and have minimal effects on blood pressure and diastolic ocular perfusion pressure in patients with primary open-angle glaucoma. Furthermore, many studies have found that timolol $0.1 \%$ gel is effective after cataract surgery: ${ }^{35,37-39}$ Lai et $\mathrm{al}^{35}$ and Kanellopoulos et $\mathrm{al}^{39}$ showed that it is more effective than latanoprost or acetazolamide, respectively, in preventing ocular hypertension early after phacoemulsification and intraocular lens implantation.

Timolol $0.1 \%$ gel is usually instilled once a day, but, in order to assess its effectiveness over time, our group 2 patients instilled the drops the evening before IVI. Instead other topical therapies (dorzolamide/timolol or brinzolamide/ timolol) with a shorter duration of action need to be usually administered twice a day. Prostaglandin analogs are instilled once a day, but are not an option for prophylaxis as they play a role in the inflammatory process, which could be one of the causes of post-IVI increases in IOP. ${ }^{40}$ It therefore, seemed to us that timolol $0.1 \%$ gel would be the most appropriate topical prophylactic therapy to reduce post-IVI IOP spikes because of its longer duration of action and greater safety.

The trends of IOP were similar in our study groups, with higher values being recorded 5 minutes after IVI (Table 4). However, only the group that received timolol 2 hours before IVI had significantly lower IOP values than the untreated group; but, we expected similar results in the group receiving timolol the evening before the injection.

We assessed the incidence of clinically significant intraocular hypertensive spikes $(>25$ or $>40 \mathrm{mmHg})$ because it is more important to evaluate the effectiveness of prophylaxis on these rather than on IOP variations, as it is thought that they are more hazardous for optic nerve health in subjects with glaucoma. ${ }^{22-26}$ Our multivariate analysis did not reveal any significant differences between the control and the treated groups in terms of spikes of $>25 \mathrm{mmHg}$, but administration of timolol $0.1 \%$ only 2 hours before IVI was significantly more effective in preventing hypertensive spikes of $>40 \mathrm{mmHg}$ than no prophylaxis (although, once again, we expected similar results in the group receiving timolol the evening before the injection).

We did not include patients with glaucoma or ocular hypertension, or those being treated with IOP-lowering medications (although they may benefit more from such prophylactic therapy) because the use of other IOP-lowering drugs may have biased the evaluation of the effectiveness of timolol prophylaxis. We also considered only IVI-naïve patients because a number of studies of small case series have found delayed and sometimes persistent ocular hypertension occurring several weeks to months after multiple IVIs of ranibizumab and/or bevacizumab in patients with exudative age-related macular disease. ${ }^{11,41,42}$

One limitation of this study is the small number of postIVI IOP measurements (after 5 and 60 minutes); it would have been useful to evaluate IOP over a longer period in order to assess the 24-hour efficacy of the prophylactic IOPlowering medication.

\section{Conclusion}

Our results showed that IOP spikes are a frequent complication of anti-VEGF IVIs: spikes of $>25 \mathrm{mmHg}$ were observed at any time in $54 \%$ of the patients in group 1, 44\% of those in group 2, and $48 \%$ of those in group 3; and spikes of $>40 \mathrm{mmHg}$ (only detected 5 minutes after IVI) were observed in $18 \%$, $16 \%$ and $2 \%$ of the patients, respectively. The incidence of hypertensive IOP 5 minutes after a ranibizumab IVI was significantly less in patients who received timolol $0.1 \%$ gel 2 hours before IVI, who also benefited from significantly greater protection against spikes $>40 \mathrm{mmHg}$. These findings suggest that the routine prophylactic use of timolol $0.1 \%$ gel 2 hours before IVI is a safe and effective means of preventing IOP spikes, reducing the need for emergency procedures, and preserving the health of the optic nerve.

\section{Acknowledgment}

The authors have no proprietary interest in any aspect of this study. This study was supported by RETINA 3000 Foundation.

\section{Author contributions}

AP, DA, and GM contributed to conception and design; AP, DA, and AFD contributed to acquisition of data; AP and AFD have performed surgical procedures; all the authors contributed to interpretation of data; and all the authors drafted the article and approved its final version.

\section{Disclosure}

The authors report no conflicts of interest in this work.

\section{References}

1. Lee YJ, Park HJ, Lee TG, et al. Primary combined photodynamic therapy and intravitreal bevacizumab injection for neovascular age-related macular degeneration. J Korean Ophthalmol Soc. 2010;51(1):35-41.

2. Smit DP, Meyer D. Intravitreal bevacizumab: an analysis of the evidence. Clin Ophthalmol. 2007;1(3):273-284.

3. Matri L, Chebil A, Kort F, et al. Intravitreal injection of triamcinolone combined with bevacizumab for choroidal neovascularization associated with large retinal pigment epithelial detachment in agerelated macular degeneration. Graefes Arch Clin Exp Ophthalmol. 2010;248(6):779-784. 
4. D'Amico DJ, Masonson HN, Patel M, et al. Pegaptanib sodium for neovascular age-related macular degeneration: two-year safety results of the two prospective, multicenter, controlled clinical trials. Ophthalmology. 2006;113(6):992-1001

5. Sampat KM, Garg SJ. Complications of intravitreal injections. Curr Opin Ophthal. 2010;21(3):178-183.

6. Falkenstein IA, Cheng L, Freeman WR. Changes of intraocular pressure after intravitreal injection of bevacizumab (avastin). Retina. 2007;27(8): 1044-1047.

7. Hollands H, Wong J, Bruen R, Campbell RJ, Sharma S, Gale J. Short-term intraocular pressure changes after intravitreal injection of bevacizumab. Can J Ophthalmol. 2007;42(6):807-811.

8. Kim JE, Mantravadi AV, Hur EY, Covert DJ. Short-term intraocular pressure changes immediately after intravitreal injections of antivascular endothelial growth factor agents. Am J Ophthalmol. 2008; 146(6):930-934.e1.

9. Bakri SJ, Pulido JS, McCannel CA, Hodge DO, Diehl N, Hillemeier J. Immediate intraocular pressure changes following intravitreal injections of triamcinolone, pegaptanib, and bevacizumab. Eye (Lond). 2009; 23(1):181-185.

10. Hoang QV, Mendonca LS, Della Torre KE, Jung JJ, Tsuang AJ, FreundKB. Effect on intraocular pressure in patients receiving unilateral intravitreal anti-vascular endothelial growth factor injections. Ophthalmology. 2012;119(2):321-326.

11. Adelman RA, Zheng Q, Mayer HR. Persistent ocular hypertension following intravitreal bevacizumab and ranibizumab injections. J Ocul Pharmacol Ther. 2010;26(1):105-110.

12. El Chehab H, Le Corre A, Agard E, et al. Effect of topical pressurelowering medication on prevention of intraocular pressure spikes after intravitreal injection. Eur J Ophthalmol. 2013;23(3):277-283.

13. Mathalone N, Arodi-Golan A, Sar S, et al. Sustained elevation of intraocular pressure after intravitreal injections of bevacizumab in eyes with neovascular age-related macular degeneration. Graefes Arch Clin Exp Ophthalmol. 2012;250(10):1435-1440.

14. Wehrli SJ, Tawse K, Levin MH, Zaidi A, Pistilli M, Brucker AJ. A lack of delayed intraocular pressure elevation in patients treated with intravitreal injection of bevacizumab and ranibizumab. Retina. 2012;32(7):1295-1301.

15. Rosenfeld PJ, Brown DM, Heier JS, et al. Ranibizumab for neovascular age-related macular degeneration. $N$ Engl J Med. 2006; 355(14):1419-1431.

16. Brown DM, Kaiser PK, Michels M, et al. Ranibizumab versus verteporfin for neovascular age-related macular degeneration. N Engl J Med. 2006 355(14):1432-1444.

17. Avery RL, Bakri SJ, Blumenkranz MS, et al. Intravitreal injection technique and monitoring: updated guidelines of an expert panel. Retina. 2014;34(Supp1 12):S1-S18.

18. Gismondi M, Salati C, Salvetat ML, et al. Short-term effect of intravitreal injection of Ranibizumab (Lucentis) on intraocular pressure. J Glaucoma. 2009;18(9):658-661.

19. Mojica G, Hariprasad SM, Jager RD, Mieler WF. Short-term intraocular pressure trends following intravitreal injections of ranibizumab (Lucentis) for the treatment of wet age-related macular degeneration. Br J Ophthalmol. 2008;92(4):584.

20. Aref AA. Management of immediate and sustained intraocular pressure rise associated with intravitreal antivascular endothelial growth factor injection therapy. Curr Opin Ophthalmol. 2012;23(2):105-110.

21. Brubaker RF. Targeting outflow facility in glaucoma management. Surv Ophthalmol. 2003;48(Suppl 1):S17-S20.

22. Michelson G, Groh MJ, Langhans M. Perfusion of the juxtapapillary retina and optic nerve head in acute ocular hypertension. Ger $J$ Ophthalmol. 1996;5(6):315-321.

23. Quigley HA, Anderson DR. Distribution of axonal transport blockade by acute intraocular pressure elevation in the primate optic nerve head. Invest Ophthalmol Vis Sci. 1977;16(7):640-644.
24. Lemos-Reis R, Moreira-Gonçalves N, Melo AB, Carneiro AM, FalcãoReis FM. Immediate effect of intravitreal injection of bevacizumab on intraocular pressure. Clin Ophthalmol. 2014;8:1383-1388.

25. Savage JA, Thomas JV, Belcher CD 3rd, Simmons RJ. Extracapsular cataract extraction and posterior chamber intraocular lens implantation in glaucomatous eyes. Ophthalmology. 1985;92(11):1506-1516.

26. Kolker AE. Visual prognosis in advanced glaucoma: a comparison of medical and surgical therapy for retention of vision in 101 eyes with advanced glaucoma. Trans Am Ophthalmol Soc. 1977;75:539-555.

27. Chang W, Chung M. Efficacy of anterior chamber paracentesis after intravitreal triamcinolone injection. Eur J Ophthalmol. 2007;17(5): 776-779.

28. Lin JM, Tsai YY, Chiu YT, Hung PT. Paracentesis before or after intravitreal injection of triamcinolone acetonide and its necessity? Am J Ophthalmol. 2006;141(5):985-986.

29. Huang WC, Lin JM, Chiang CC, Tsai YY. Necessity of paracentesis before or after intravitreal injection of bevacizumab. Arch Ophthalmol. 2008;126(9):1314-1315.

30. Ozcaliskan S, Ozturk F, Yilmazbas P, Beyazyildiz O. Effect of dorzolamide-timolol fixed combination prophylaxis on intraocular pressure spikes after intravitreal bevacizumab injection. Int $J$ Ophthalmol. 2015;8(3):496-500.

31. Murray CD, Wood D, Allgar V, Walters G, Gale RP. Short-term intraocular pressure trends following intravitreal ranibizumab injections for neovascular age-related macular degeneration-the role of oral acetazolamide in protecting glaucoma patients. Eye (Lond). 2014;28(10): 1218-1222.

32. Kim GN, Han YS, Chung IY, Seo SW, Park JM, Yoo JM. Effect of Dorzolamide/Timolol or Brinzolamide/Timolol prophylaxis on intravitreal anti-VEGF injection-induced intraocular hypertension. Semin Ophthalmol. 2013;28(2):61-67.

33. Frenkel MP, Haji SA, Frenkel RE. Effect of prophylactic intraocular pressure-lowering medication on intraocular pressure spikes after intravitreal injections. Arch Ophthalmol. 2010;128(12):1523-1527.

34. Dailey RA, Brubaker RF, Bourne WM. The effects of timolol maleate and acetazolamide on the rate of aqueous formation in normal human subjects. Am J Ophthalmol. 1982; 93(2):232-237.

35. Lai JS, Chua JK, Leung AT, Lam DS. Latanoprost versus timolol gel to prevent ocular hypertension after phacoemulsification and intraocular lens implantation. J Cataract Refract Surg. 2000;26(3):386-391.

36. Quaranta L, Katsanos A, Floriani I, Riva I, Russo A, Konstas AG. Circadian intraocular pressure and blood pressure reduction with timolol $0.5 \%$ solution and timogel $0.1 \%$ in patients with primary open-angle glaucoma. J Clin Pharmacol. 2012;52(10):1552-1557.

37. Byrd S, Singh K. Medical control of intraocular pressure after cataract surgery. J Cataract Refract Surg. 1998;24(11):1493-1497.

38. Haimann MH, Phelps CD. Prophylactic timolol for the prevention of high intraocular pressure after cataract extraction; a randomized, prospective, double-blind trial. Ophthalmology. 1981;88(3):233-238.

39. Kanellopoulos AJ, Perry HD, Donnenfeld ED. Timolol gel versus acetazolamide in the prophylaxis of ocular hypertension after phacoemulsification. J Cataract Refract Surg. 1997;23(7):1070-1074.

40. Sniegowski M, Mandava N, Kahook MY. Sustained intraocular pressure elevation after intravitreal injection of bevacizumab and ranibizumab associated with trabeculitis. Open Ophthalmol J. 2010;4:28-29.

41. Bakri SJ, McCannel CA, Edwards AO, Moshfeghi DM. Persistent ocular hypertension following intravitreal ranibizumab. Graefes Arch Clin Exp Ophthalmol. 2008;246(7):955-958.

42. Tseng JJ, Vance SK, Della Torre KE, et al. Sustained increased intraocular pressure related to intravitreal antivascular endothelial growth factor therapy for neovascular age-related macular degeneration. J Glaucoma. 2012;21(4):241-247. 


\section{Publish your work in this journal}

Clinical Ophthalmology is an international, peer-reviewed journal covering all subspecialties within ophthalmology. Key topics include: Optometry; Visual science; Pharmacology and drug therapy in eye diseases; Basic Sciences; Primary and Secondary eye care; Patient Safety and Quality of Care Improvements. This journal is indexed on

Submit your manuscript here: http://www.dovepress.com/clinical-ophthalmology-journal
PubMed Central and CAS, and is the official journal of The Society of Clinical Ophthalmology (SCO). The manuscript management system is completely online and includes a very quick and fair peer-review system, which is all easy to use. Visit http://www.dovepress.com/ testimonials.php to read real quotes from published authors. 